\title{
A “One Accessory and One Guidewire-in-One Channel” Technique in a Patient with Billroth II Anastomosis
}

\author{
Kook Hyun Kim, Sung Bum Kim and Tae Nyeun Kim \\ Division of Gastroenterology and Hepatology, Department of Internal Medicine, Yeungnam University College of Medicine, Daegu, \\ Korea
}

An 82-year-old patient with cirrhosis visited the emergency department because of a sudden onset of right upper quadrant pain for 3 days. Twenty-five years earlier, he underwent a subtotal gastrectomy with Billroth II anastomosis because of gastric cancer. Recently, he experienced several episodes of hepatic arterial chemoembolization due to hepatocellular carcinoma. His initial blood chemistry was as follows: white blood cell count, $15,700 / \mathrm{mm}^{3}$; hemoglobin, $8.2 \mathrm{~g} / \mathrm{dL}$; platelet count, $62,000 / \mathrm{mm}^{3}$; C-reactive protein, $11.8 \mathrm{mg} / \mathrm{dL}$; aspartate aminotransferase, $117 \mathrm{IU} / \mathrm{L}$; alanine aminotransferase, $59 \mathrm{IU} /$ $\mathrm{L}$; total bilirubin, $3.1 \mathrm{mg} / \mathrm{dL}$; alkaline phosphatase, $127 \mathrm{IU} /$ $\mathrm{L}$; and gamma-glutamyl transferase, 252 IU/L. Abdominal computed tomography revealed a dilated common bile duct (CBD) with suspicious biliary sludge and a distended gallbladder. Initially, an ampullary approach via endoscopic retrograde cholangiopancreatography (ERCP) using a side-viewing endoscope (TGF-240; Olympus Optical Co., Kuroishi, Japan) was attempted but failed because of acute angulation of the afferent loop. Thus, the endoscope was changed to a cap-fitted forward-viewing endoscope (GIF-H260; Olympus Optical) with a diameter of $2.8 \mathrm{~mm}$ working channel. A series of attempts for biliary cannulation using a standard ERCP catheter with a straight tip (Cook Medical Inc.,Winston-Salem, NC,

Received: April 1,2020 Revised: May 3, 2020

Accepted: May 14, 2020

Correspondence: Kook Hyun Kim

Division of Gastroenterology and Hepatology, Department of Internal Medicine, Yeungnam University College of Medicine, 170 Hyunchung-ro, Nam-gu, Daegu 42415, Korea

Tel: +82-53-620-3576, Fax: +82-53-654-8386, E-mail: kimkh@yu.ac.kr ORCID: https://orcid.org/0000-0001-7786-7882

(c) This is an Open Access article distributed under the terms of the Creative Commons Attribution Non-Commercial License (http://creativecommons.org/ licenses/by-nc/3.0) which permits unrestricted non-commercial use, distribution, and reproduction in any medium, provided the original work is properly cited.
USA) with or without preloaded guidewire were unsuccessful because of the flat ampulla and tortuous CBD (Fig. 1). ${ }^{1-5}$

The "two accessory-in-one channel" technique was modified into a "one accessory and one guidewire-in-one channel" method owing to the small working channel. ${ }^{6}$ An endobiliary forceps (Aomori Olympus Co.) and a 0.025-inch guidewire (straight type, Visiglide $2^{\mathrm{TM}}$; Olympus) were fitted into the small-caliber channel of the forward-viewing endoscope. The lower margin of the ampulla was carefully grasped with the endobiliary forceps and pulled gently and slightly to stabilize and straighten the CBD (Fig. 2). Then, with cautious manipulation, an 0.025-inch guidewire with a straight tip was advanced parallel to the forceps and glided into the CBD (Fig. 3, Supplementary Video 1). Finally, an ERCP catheter was advanced into the bile duct over the guidewire. After obtaining the optimal cholangiogram, a 7-Fr double pigtail stent, without endoscopic sphincterotomy, was placed into the CBD for biliary decompression. Three days later, a follow-up ERCP was performed. A precut incision using a needle knife (Boston Scientific Microvasive, Cork, Ireland) was made over the plastic stent. An 8-mm dilating catheter (Fusion ${ }^{\circledR}$ Titan $^{\mathrm{TM}}$; Cook Medical) was advanced over the guidewire, and an endoscopic papillary balloon dilation was performed. After removal of the plastic stent, some sludge was extracted using a retrieval balloon catheter.

Biliary deep cannulation is still challenging in patients with surgically altered anatomy. Herein, we present a novel "one accessory and one guidewire-in-one channel" technique to facilitate selective cannulation in a case of failed cannulation using the conventional method. The utmost useful indications of this technique are as follows: First, when a major ampulla is positioned at the proximal margin of a diverticulum, the ampulla is easily pushed into the diverticulum when probing with an ERCP catheter. Second, when the ampullary orifice 


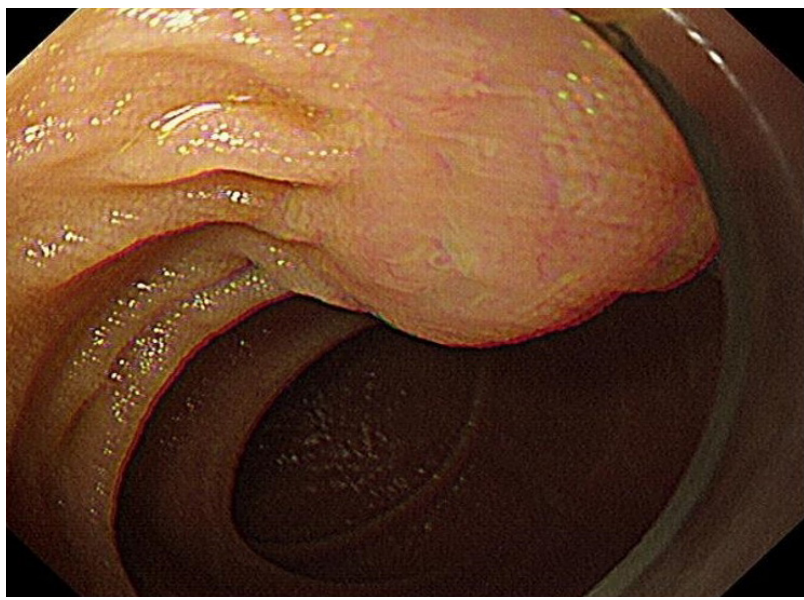

Fig. 1. The endoscopic image using a cap-fitted forward-viewing endoscope shows a reversely oriented ampulla of Vater, which was not prominent. Cannulation attempts using a standard cannulation catheter with a straight tip failed because of the flat ampulla and tortuous bile duct.

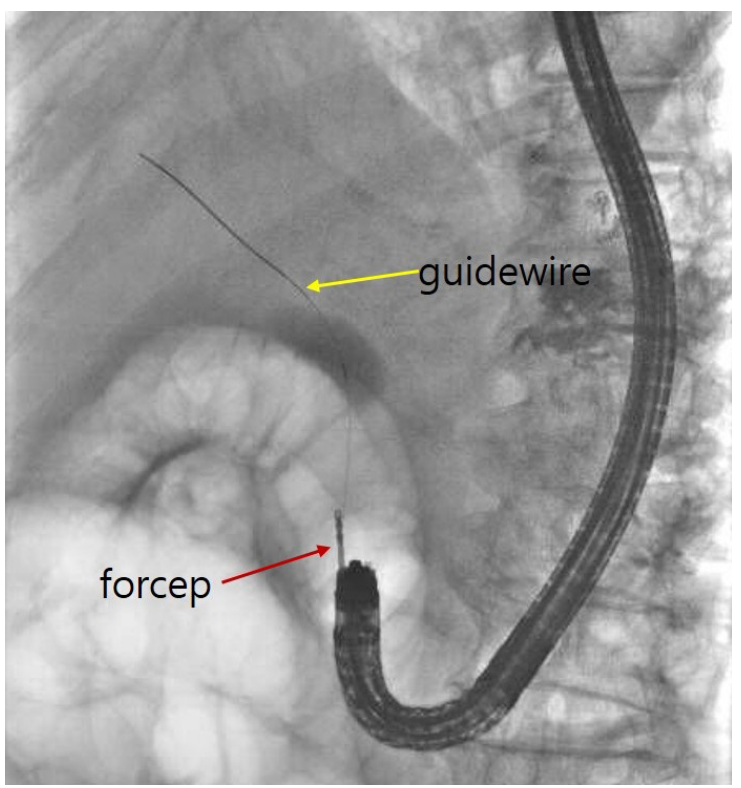

Fig. 3. The fluoroscopic image shows a 0.025 -inch guidewire passing through the same working channel parallel to the endobiliary forceps grasping the lower margin of the ampulla.

is flat, distorted, or facing the opposite direction, pulling the ampullary margin is helpful for obtaining an appropriate en face view to look up to the papilla for swift cannulation. To the best of our knowledge, this is the first report of a technique for enhancing the biliary access in patients with subtotal gastrectomy with Billroth II anastomosis.

\section{Conflicts of Interest}

The authors have no potential conflicts of interest.

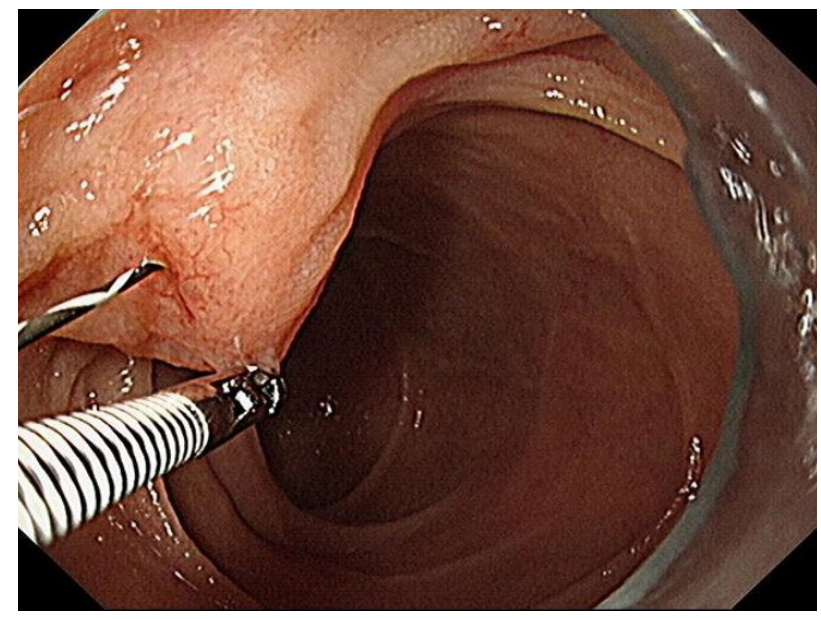

Fig. 2. Gentle grasping of the lower margin of the ampulla and pulling the mucosa with an endobiliary forceps can enhance the stabilization of the ampulla and straighten the bile duct. Then, a 0.025-inch guidewire was manipulated carefully and cannulated successfully into the bile duct.

Funding

None.

Supplementary Material

Video 1. Endoscopic retrograde cholangiopancreatography (ERCP) is performed using a forward-viewing endoscope because of the Billroth II anastomosis. Several attempts of biliary cannulation using an ERCP catheter with a straight tip failed. An endobiliary forceps was used to grasp and pull the margin of the ampulla of Vater, while a 0.025 -inch guidewire was manipulated and cannulated into the bile duct (https://doi.org/10.5946/ ce.2020.087.v001).

ORCID
Kook Hyun Kim: Sung Bum Kim:

Tae Nyeun Kim: https://orcid.org/0000-0001-7786-7882 https://orcid.org/0000-0001-8447-2176 https://orcid.org/0000-0003-4178-2056

\section{REFERENCES}

1. Deriban G, Nojkov B, Mishevski J. Side-viewing duodenoscope retroflexion method for bile duct cannulation and sphincterotomy in patient with Billroth II anatomy. Dig Endosc 2018;30:115-116.

2. Chun SY, Kim JH, Moon SH, et al. The loop-tip wire for selective cannulation during ERCP in patients with Billroth II anastomosis: a preliminary feasibility study. Hepatogastroenterology 2014;61:897-901.

3. Lee K, Choi JW, Lee Y, Han JH, Park SM. Papillary cannulation facilitated by submucosal saline injection into an intradiverticular papilla. Clin Endosc 2019;52:83-86

4. Jang JS, Lee S, Lee HS, et al. Efficacy and safety of endoscopic papillary balloon dilation using cap-fitted forward-viewing endoscope in patients who underwent Billroth II gastrectomy. Clin Endosc 2015;48:421-427.

5. Kim YH, Kwon CI, Kim DY, et al. [Case series of ERCP and EST with rotatable papillotome (Autotome ${ }^{\circledR}$ ) in patients with Billoth II gastrectomy]. Korean J Gastrointest Endosc 2007;35:445-450.

6. Kim KH, Kim TN. A new technique for difficult biliary cannulation using endobiliary forceps in a patient with a periampullary diverticulum. Endoscopy 2017;49:824-826. 